\title{
Effect of incorporation of blackberry particles obtained by freeze drying on physicochemical properties of edible films
}

\author{
Nogueira, G. F. ${ }^{\text {; }}$ Fakhouri, F. M. ${ }^{\text {bc }}$; Oliveira, R. A. ${ }^{\mathbf{a}^{*}}$ \\ a School of Agricultural Engineering, University of Campinas, Campinas, SP, Brazil \\ b School of Chemical Engineering, University of Campinas, Campinas, SP, Brazil \\ c School of Food Engineering, Federal University of Grande Dourados, Dourados, MS, \\ Brazil
}

*E-mail of the corresponding author: augustus@feagri.unicamp.br

\begin{abstract}
This research work aimed to evaluate the physicochemical properties of arrowroot starch films plasticized with glycerol and incorporated in filmforming solution directly (D) and by sprinkling (S) with 0\%, 20\%, 30\%, 40\% (mass blackberry solids / biopolymer mass) of blackberry pulp (BL) powder and freeze dried microencapsulated blackberry pulp (ML) using mixture of gum arabic and arrowroot starch (1: 1, mass / mass). Thickness, water solubility and water vapour permeability of the films significantly increased with increasing concentration of blackberry powder. Compared to arrowroot starch film (0\%), the surface of films with BL and ML powder became irregular and rough.
\end{abstract}

Keywords: Lyophilization; microstructure; water solubility; water vapor permeability; packing. 


\section{Introduction}

Fruit pulp has great potential to be incorporated in the film-forming solution in order to produce edible films with functional compounds such as preservation agents (antimicrobial or antioxidant compounds), innovative colours and flavours, as well as suitable mechanical and barrier properties of the biopolymer.[1] Thus, blackberry is a fruit that has great potential to supply these requirements and be used in combination with arrowroot starch to form a biopolymer matrix to create edible films. Blackberry (Rubus fruticosus) cv. Tupy is a fruit rich in anthocyanins and phenolic compounds, which has high antioxidant activity.[2] However, using its beneficial effects is limited because its bioactive compounds exhibit instability when exposed to high temperature, light, oxygen, among other conditions, changing their functional and antioxidative properties.[3] This situation can be mitigated by applying microencapsulation technologies in order to protect it from unfavourable environments. Freeze drying is a technological process based on dehydration by sublimation of a frozen product resulting in a dry material.[4] These processes can be used as encapsulation method when it incorporates 'active' material within a protective matrix, which is essentially inert to the encapsulated material.[5] Recently, the incorporation of micro and nano particles in film-forming solution to produce starch films with modified structure and properties have shown promise.[6] Therefore, the objective of this work was to incorporate directly and by sprinkling, blackberry pulp powder and microencapsulated blackberry pulp powder in arrowroot starch film-forming solution.The influence of type of incorporation and variation of concentration of blackberry powders on physicochemical properties of edible films were investigated.

\section{Materials and Methods}

\subsection{Materials}

In this work, frozen fruits of blackberry (Rubus fruticosus), cv Tupy, were acquired from "Agro Monte Verde Eirelli", Cambuí - MG, Brazil. Blackberry soluble solids content was $9^{\circ}$ Brix, determined with digital refractometer with 0-90 ${ }^{\circ}$ Brix range and $0.2{ }^{\circ}$ Brix resolution (Reichert, Model AR200, USA). Blackberry pulp presented total solids content of $10.3 \mathrm{~g} / 100 \mathrm{~g}$ of pulp. For microencapsulation of blackberry pulp, arrowroot starch and Instantgum ${ }^{\circledR}$ gum arabic (Colloides Naturels, São Paulo, Brazil) were used as encapsulating agents. In elaboration of edible biodegradable films, arrowroot starch containing $15.24 \pm 0.19 \%$ of water, $0.40 \pm 0.03 \%$ of protein, $0.12 \pm 0.01 \%$ of fat, $0.33 \pm$ $0.01 \%$ of ash and $83.91 \pm 0.00 \%$ of carbohydrates [7] and amylose content of $35.20 \pm$ $1.63 \%$, determined according to the methodology described by Martinez and Cuevas (1989), with adaptations [8], was used as film-forming matrix and glycerol P.A. (Reagen, Quimibrás Indústrias Químicas S.A.- Rio de Janeiro, Brazil) as plasticizing agent. 


\subsection{Microencapsulation of blackberry pulp by freeze drying}

Blackberry pulp was obtained by grinding the fruits in a blender, filtered through a sieve to remove the seeds, and homogenized. Blackberry pulp was added to the encapsulating agent, arrowroot starch and gum arabic mixture (1: 1 mass / mass) in a ratio of 1:1.78 (mass / mass, blackberry pulp solids for encapsulating agent). Solution of encapsulating agent and blackberry pulp was performed in a mixer type homogenizer at room temperature for 5 minutes. Portions of frozen blackberry pulp with and without encapsulating agent was lyophilized (Mod. 501, Edwards Pirani, Crawley, West Sussex, UK), with an initial temperature of $-40{ }^{\circ} \mathrm{C}$, pressure of $0.1 \mathrm{mmHg}$, and final temperature of $25^{\circ} \mathrm{C}$ per $2 \mathrm{~h}$, with total cycle time of $48 \mathrm{~h}$. The resulting product was ground in a hammer mill (MR Manesco and Ranieri LTDA, model MR020, Piracicaba- Brazil), sieved and stored in polyethylene packages in desiccators, for further analysis.

\subsection{Incorporation of blackberry into film-forming suspension}

\subsubsection{Preparation of film-forming suspension.}

Film-forming suspension was obtained by dispersing arrowroot starch in distilled water (4\%, mass / mass, as optimized by Nogueira, Fakhouri \& Oliveira, [9]). This suspension was heated to $85 \pm 2{ }^{\circ} \mathrm{C}$ in a thermostatic bath (TECNAL, Brazil), with constant agitation, for about 5 minutes. The freeze dried blackberry pulp (BL) and the freeze dried microencapsulated blackberry pulp (ML) were added to film-forming suspension in different concentrations, $0 \%, 20 \%, 30 \%$ and $40 \%$ (mass/mass of dry starch) in two different ways. The first one consisted of direct incorporation in film-forming suspension and the second one was by sprinkling into film-forming suspension. Glycerol was added to the solution at concentration of $17 \%$ (mass/mass of total solids, [9]).

\subsubsection{Direct incorporation of blackberry powder into film-forming suspension (D.}

Freeze dried blackberry pulp (BL) and freeze dried microencapsulated blackberry pulp (ML) were added directly into film-forming suspension and homogenized in previously mentioned proportions. Aliquots of $25 \mathrm{~mL}$ of resulting suspensions were distributed on support plates (12 cm diameter). Films were dried at room temperature $\left(25 \pm 5^{\circ} \mathrm{C}\right)$, until they could be easily removed from the plates, approximately for $24 \mathrm{~h}$. Films were conditioned at $25{ }^{\circ} \mathrm{C}$ and $55 \pm 3 \%$ of relative humidity for $48 \mathrm{~h}$, before their characterization. 


\subsubsection{Incorporation of blackberry powder by sprinkling into film-forming suspension (S).}

Aliquots of $25 \mathrm{~mL}$ of resulting film-forming suspension were distributed on support plates (12 cm diameter). Freeze dried blackberry pulp (BL) and freeze dried microencapsulated blackberry pulp (ML) were dispersed through a stainless steel sieve (53 mesh), homogeneously in all the surface area of film-forming suspension already disposed on the plates. Then, films were dried for $24 \mathrm{~h}$ at room temperature $\left(25 \pm 5^{\circ} \mathrm{C}\right)$. After drying, films were removed from the support plates and conditioned at $25{ }^{\circ} \mathrm{C}$ and $55 \pm 3 \%$ relative humidity for $48 \mathrm{~h}$, before their characterization.

\subsection{Films characterization}

\subsubsection{Microstructure}

Electronic Scanning Electron Microscope with X-ray Dispersive Energy Detector (SEM) bench (model of MEV: Leo 440i, model of EDS: 6070, Leo 440i - LEO Electron Microscopy/Oxford- Cambridge, England) was used to observe morphological characteristics of surface and cross section developed for sample of the films formulations.

\subsubsection{Film Thickness and solubility in water}

Films thicknesses were measured with accuracy of $\pm 0.001 \mathrm{~mm}$, at ten different regions of the film, using a micrometer (Mitutoyo brand, model MDC 25M, MFG / Japan).

Water solubility of films was determined according to the method proposed by Gontard, Guilbert, and Cuq. [10] and expressed according to Equation (1).

$$
\text { Solubilized material }(\%)=\frac{\mathrm{m}_{\mathrm{si}}-\mathrm{m}_{\mathrm{sf}}}{\mathrm{m}_{\mathrm{si}}} \times 100
$$

In which 'msi' is the initial dry mass of the films (g), 'msf' is the final dry mass of the nonsolubilized films (g).

\subsubsection{Water vapor permeability}

Water vapor permeability rate of the films was determined gravimetrically based on ASTM E96-80 method [11], using an acrylic cell, with a central opening (diameter of $4.3 \mathrm{~cm}$ ), in which the film was fixed. The bottom of the cell was filled with dried calcium chloride, creating a dry environment inside $\left(0 \%\right.$ relative humidity at $\left.25^{\circ} \mathrm{C}\right)$. This cell was placed in desiccator containing saturated sodium chloride (75 $\pm 3 \% \mathrm{RH})$, equalized for $48 \mathrm{~h}$ previously to analysis. Water vapor transferred through the film was determined by mass gain of calcium chloride. The cell weight was recorded daily for, at least, 7 days. The film thickness consisted on the average of 5 random measurements made on different parts of 
the samples. The water vapor permeation rate (PVA) was performed in triplicate and calculated by Equation (2).

$$
P V A=\frac{\bullet}{A x \Delta p} x \dot{\mathrm{M}}
$$

In which 'PVA' is permeability to water vapor (g.mm / $\mathrm{m}^{2}$.day.kPa), 'e' is mean film thickness, ' $\mathrm{A}$ ' is permeation area $\left(\mathrm{m}^{2}\right)$, ' $\Delta \mathrm{p}$ ' is partial vapor pressure difference between two sides of films $\left(\mathrm{kPa}\right.$, at $\left.25^{\circ} \mathrm{C}\right)$, ' $\dot{\mathrm{M}}$ ' is absorbed moisture rate, calculated by linear regression of weight gain and time, in steady state (g/day).

\subsubsection{Statistical analysis}

Significant differences between average results were evaluated by analysis of variance (ANOVA) and Tukey test at 5\% level of significance, using SAS software (Cary, NC, USA).

\section{Results and discussion}

Differences in microstructure of the films can be visualized in Figure 1, by scanning electron microscopy (SEM). Control film (0\%) presented organized and continuous polymer matrix and regular surface (Figure 1 A-C). Films developed with $40 \%$ of blackberry presented rougher and irregular surfaces and exhibited structural characteristics directly related to those observed for BL and ML powders, which consequently hampered its solubilization. The cross-section images of 40\% BLD and MLD films (Figure 2 D-F and $\mathrm{J}-\mathrm{L}$, respectively), showed continuous regions and disorganized regions due to the presence of BL and ML particle within arrowroot starch matrix formed during the films drying. BL and ML particles were integrated in arrowroot starch matrix, showing good compatibility between materials. Using sieve to sprinkle BL and ML powder over the film-forming suspension allowed falling homogenously over the entire surface area of films. It can be seen in Figure 2 G-I, in which, when 40\% ML were sprayed under the film-forming suspension. Some regions with BL and ML agglomerations could also be observed in films for both types of incorporation. This may be due to poor dispersion of powders in high concentrations in the film-forming solution, given its high viscosity. 
Effect of incorporation of blackberry particles obtained by freeze drying on physicochemical properties of edible films

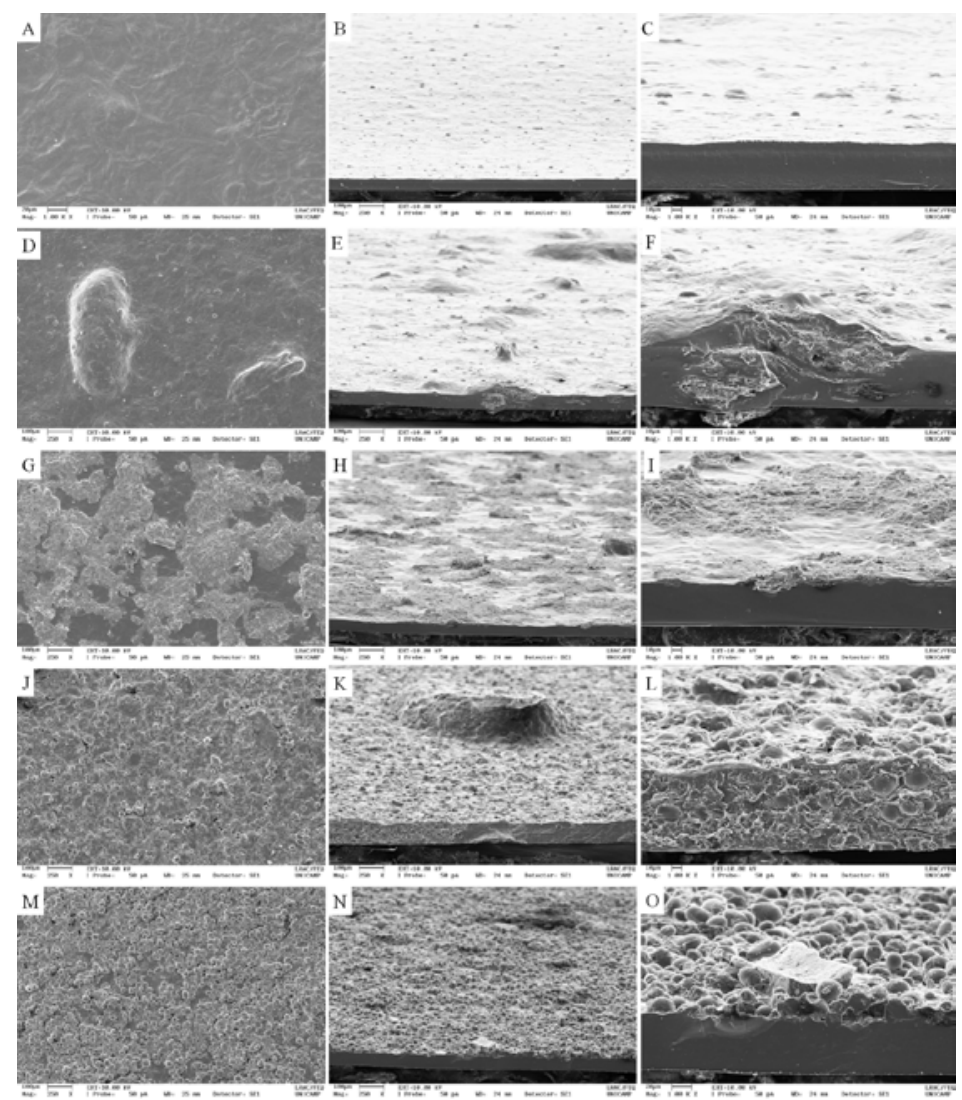

Figure 1. SEM images of the films with $0 \%$ and $40 \%$ of freeze dried blackberry pulp (BL) and freeze dried microencapsulated blackberry pulp $(M L)$ incorporated directly $(D)$ and by sprinkling (S): (A, B and C) surface and cross section of control film; (D, E and F) surface and cross section of 40\% BLD film; (G, $H$ and I) surface and cross section of $40 \%$ BLS film; (J, K and L) surface and cross section of 40\% MLD film; (J, K and L) surface and cross section of 40\% MLS film. Images $A, C, F, I, L$ and $O$ with $250 x$ magnification and images $B, D, E, G, H, J, K, M$ and $N$ with 1000x magnification.

Thickness of films significantly increased $(\mathrm{p}<0.05)$ with increasing concentration of $\mathrm{BL}$ and ML powder incorporated directly (D) and by sprinkling (S) as compared to control film (0\%) (Table 1), although, in all cases, the film-forming suspension volume by plate area remained constant. The increased solid content and possible agglomeration of BL and ML in polymer matrix, evidenced by prominences on the surface of films by SEM (Figure 1), could explain this result. 
Table 1. Thickness, solubility in water and permeability to water vapor of films with $0 \%, 20 \%, 30 \%$ and $40 \%$ of freeze dried blackberry pulp (BL) and freeze dried microencapsulated blackberry pulp (ML) directly incorporated (D) and by sprinkling (S).

\begin{tabular}{|c|c|c|c|}
\hline Films & $\begin{array}{c}\text { Thickness } \\
(\mathrm{mm})\end{array}$ & $\begin{array}{c}\text { Solubility in water } \\
(\%)\end{array}$ & $\begin{array}{l}\text { Permeability to water vapor } \\
\text { (g.mm/m².day.kPa) }\end{array}$ \\
\hline $0 \%$ & $0.065 \pm 0.005^{\mathrm{d}}$ & $14.18 \pm 0.26^{\mathrm{g}}$ & $3.62 \pm 0.27$ hdfge \\
\hline $20 \%$ BLD & $0.092 \pm 0.005 \mathrm{dc}$ & $21.64 \pm 0.93 \mathrm{fe}$ & $3.03 \pm 0.10$ hfge \\
\hline $30 \%$ BLD & $0.121 \pm 0.014$ bdaac & $22.76 \pm 1.13^{\mathrm{dfe}}$ & $6.63 \pm 0.39$ bc \\
\hline $40 \%$ BLD & $0.154 \pm 0.054$ bac & $26.14 \pm 1.16^{\text {dce }}$ & $5.40 \pm 0.47$ dce \\
\hline $20 \%$ BLS & $0.082 \pm 0.006^{d}$ & $19.26 \pm 1.68^{\mathrm{fe}}$ & $1.67 \pm 0.12^{\mathrm{h}}$ \\
\hline $30 \%$ BLS & $0.098 \pm 0.013^{\text {bdc }}$ & $24.65 \pm 1.95$ dce & $2.38 \pm 0.45^{\mathrm{hg}}$ \\
\hline $40 \%$ BLS & $0.113 \pm 0.016$ bdac & $27.98 \pm 2.69$ bc & $3.47 \pm 0.14$ hfge \\
\hline 20\% MLD & $0.150 \pm 0.024$ bac & $21.74 \pm 1.70^{\mathrm{fe}}$ & $2.43 \pm 0.36 \mathrm{hg}$ \\
\hline $30 \%$ MLD & $0.146 \pm 0.022^{\text {bac }}$ & $22.18 \pm 0.36^{\mathrm{dfe}}$ & $7.80 \pm 0.07$ ba \\
\hline 40\% MLD & $0.154 \pm 0.010^{\text {ba }}$ & $23.69 \pm 0.77$ dfce & $9.23 \pm 0.47^{\mathrm{a}}$ \\
\hline $20 \%$ MLS & $0.147 \pm 0.017$ bac & $27.14 \pm 2.45^{\mathrm{dc}}$ & $4.42 \pm 0.17$ dfge \\
\hline $30 \%$ MLS & $0.153 \pm 0.005^{\text {bac }}$ & $33.89 \pm 2.50^{\text {a }}$ & $5.08 \pm 1.87$ dfce \\
\hline $40 \%$ MLS & $0.173 \pm 0.011^{\mathrm{a}}$ & $32.33 \pm 1.39$ ba & $5.57 \pm 1.05^{\mathrm{dc}}$ \\
\hline
\end{tabular}

*Same letters in the same column show no statistical difference $(\mathrm{p}>0.05)$.

Incorporated films with BL and ML by sprinkling were more water soluble than films with blackberry powder incorporated directly. Differently to direct incorporation, the incorporation by sprinkling allowed particles of powder stayed only in the surface of the films. As blackberry powders were porous and showed a high hydrophilicity, it is believed that, when the films were immersed in water, the particles rehydrated rapidly leading to their solubilization. Solubilization of the particles probably created holes in the surface of the films, which allowed the acess of water molecules into the starch matrix facilitating their solubilization.

Films with only 20\% BL and ML presented lower water vapor permeability rates than the $0 \%$ film. This behavior was attributed to a better dispersion of blackberry powder at low concentrations in the film-forming solution increasing compactness of the films, which may have hindered the passage of water molecules. It is also possible that presence of blackberry powder particles within the starch matrix, as well as on the surface, has introduced a tortuous path for the passage of water molecules, which may have led to a decreasing behavior in water vapor permeability. At concentrations above $30 \%$, there was an increase in water vapor permeability due to the presence of agglomerated blackberry dust particles. 
Effect of incorporation of blackberry particles obtained by freeze drying on physicochemical properties of edible films

\section{Conclusions}

The type of incorporation and concentration of the blackberry into filmogenic solution (directly or by sprinkling) influenced the structure, thickness, water solubility and permeability to water vapor of resulting films.

\section{References}

[1] Espitia, P.J.P.; Du, W.-X.; Avena-Bustillos, R.D.J.; Soares, N.D.F.F.; McHugh, T. H. Edible films from pectin: Physical-mechanical and antimicrobial properties - A review. Food Hydrocolloids 2014, 35, 287-296.

[2] Machado, A.P.F.; Pasquel-Reátegui, J.L.; Barbero, G.F., Martínez, J. Pressurized liquid extraction of bioactive compounds from blackberry (Rubus fruticosus L.) residues: a comparison with conventional methods. Food Research International 2015, 77, 675-683.

[3] Ferrari, C.C.; Ribeiro, C.P.; Aguirre, J.M. Spray drying of blackberry pulp using maltodextrin as carrier agent. Brazilian Journal of Food Technology 2012, 15, 157165.

[4] Yamashita, C.; Chung, M.M.S.; dos Santos, C.; Mayer, C.R.M.; Moraes, I.C.F.; Branco, I.G. Microencapsulation of an anthocyanin-rich blackberry (spp.) by-product extract by freeze-drying. LWT - Food Science and Technology 2017, 84, 256-262.

[5] Ré, M.I. Microencapsulation by spray drying. Drying Technology 1998, 16, 11951236.

[6] Shi, A.-M.; Wang, L.-J.; Li, D.; Adhikari, B. Characterization of starch filmscontaining starch nanoparticles: part 1: Physical and mechanical properties. Carbohydrate Polymers 2013, 96, 593-601.

[7] A.O.A.C. Official Methods of Analysis. 18th ed. Association of Official Analytical Chemists, Gaithersburg, Maryland, 2006.

[8] Zavareze, E. da R.; El Halal, S.L.M.; Pereira, J.M.; Radünz, A.L.; Elias, M.C.; Dias, A.R.G. Chemical characterization and extraction yield of rice starch with different amylose contents. Brazilian Journal of Food Technology 2009, II SSA, janeiro.

[9] Nogueira, G.F.; Fakhouri, F.M.; de Oliveira, R.A. Extraction and characterization of arrowroot (Maranta arundinaceae L.) starch and its application in edible films. Carbohydrate Polymers 2018, https://doi.org/10.1016/j.carbpol.2018.01.024

[10] Gontard, N.; Guilbert, S.; Cuq, J.L. Edible wheat gluten films: influence of the main process variables on film properties using response surface methodology. Journal of Food Science 1992, 57, 190-199.

[11] ASTM. Standard test methods for water vapor transmission of materials. Method E9680. In: Annual book of American Standard Testing Methods. Philadelphia: ASTM, 1989. 